\title{
Ultraviolet Radiation for Microorganism Inactivation in Wastewater
}

\author{
Brahmi Mounaouer $^{1 *}$, Hassen Abdennaceur ${ }^{2}$ \\ ${ }^{1}$ Water Research and Technology Center, Borj Cédria Science and Technology Park, Soliman, Tunisia; ${ }^{2}$ University Tunis Cartage, \\ Tunis, Tunisia. \\ Email: *brahmounaouer@yahoo.fr
}

Received October $25^{\text {th }}, 2011$; revised November $28^{\text {th }}, 2011$; accepted December $29^{\text {th }}, 2011$

\begin{abstract}
The purpose of this research stream is to evaluate the kinetics of bacterial strains of Pseudomonas aeruginosa, to establish the influence of UV doses on the kinetics of disinfection, to study UV-resistant strains of Pseudomonas aeruginosa, and to underline the influence of suspended solids on the inactivation kinetics of these strains. Furthermore, and due to the lack of readily available information about the influence of temperature on microorganism inactivation processes subsequent to inactivation with UV radiation, a series of batch studies were performed at $5^{\circ} \mathrm{C}, 25^{\circ} \mathrm{C}, 37.5^{\circ} \mathrm{C}$ and $50^{\circ} \mathrm{C}$. This paper investigates the impact of UV irradiation on bacterial strains of $P$. aeruginosa inactivation in both primary and secondary wastewater effluents and to show the influence of filtration in the process of disinfection of water by UV irradiaton. Our results indicate that the effect of temperature within the normal operating range of most treatment plants, i.e., $25^{\circ} \mathrm{C}$ to $37.5^{\circ} \mathrm{C}$, was found to be not statistically significant on the kinetics of the UV disinfection process. However, the kinetics of the UV disinfection process was highly affected by system operating at extreme temperatures, i.e., at 10 and $50^{\circ} \mathrm{C}$. In a temperature range of $25^{\circ} \mathrm{C}$ to $37.5^{\circ} \mathrm{C}$, the inactivation of $P$. aeruginosa strains varied according to the incubation time and did not exceed 4 U-Log. Consequently, having more than $10^{2}$ organisms $/ 100 \mathrm{ml}$ of $P$. aeruginosa in treated wastewater would cause serious health and environmental problems. Low inactivation was observed when the operating temperature was reduced to $10^{\circ} \mathrm{C}$ regardless of the incubation time tested. In contrast, a considerable increase in the inactivation rate was noted when the temperature of the disinfected wastewater was increased to $50^{\circ} \mathrm{C}$. Hence, as $5^{\circ} \mathrm{C}$ and $50^{\circ} \mathrm{C}$ are outside the operating range of most treatment plants, as in our country, Tunisia, it is reasonable to assume that the effect of temperature change on the kinetics of UV disinfection process is negligible.
\end{abstract}

Keywords: Pseudomonas aeruginosa Inactivation; Disinfection; Ultraviolet UV; Temperature

\section{Introduction}

Securing water supplies suitable for human consumption has become an increasingly complex undertaking in many parts of the world, particularly for communities in rural areas of less developed countries. Diseases such as cholera, typhoid fever and shigellosis for example are wellknown water-borne diseases, which can cause a staggering number of deaths annually [1].

Municipal wastewater generally requires disinfection to meet regulatory microbial limits. The main objective of disinfection is to reduce the concentration of waterborne pathogens to a level below the infective limit. To meet this objective, disinfection must inactivate a wide range of bacteria, viruses, and protozoa in a variety of wastewaters. Disinfection may be accomplished by chemical or physical means. Ultraviolet-C (UV-C) radiation has been suggested as one of the successful disinfection practices for water treatment. Therefore, UV-disinfection

*Corresponding author. has become a practical solution for safe disinfection of water.

For many years, chlorination has been the standard method of water disinfection. Chlorine is used in most water treatment facilities to kill harmful micro-organisms in drinking water that cause serious diseases. Albeit being effective, the chlorine itself causes many health problems such as asthma, cancer, fertility problems, heart disease, eczema and birth defects, in addition to the unpleasant smell and taste of chlorinated water [2]. Consequently, UV disinfection has gained widespread use for municipal wastewater, and more recently, interest in using UV for water reuse applications has increased [3]. UV disinfection has several inherent advantages over all other disinfection methods. In particular, no chemical consumption thereby eliminating large scale storage, no transportation, handling and potential safety hazards, low contact time and reduced space requirements since no contact basin is necessary, no harmful by-products are 
formed as a minimum number of, or no, moving parts and high reliability and low energy requirements [4]. Ultraviolet disinfection thus solves the environmental and safety problems and is cost-effective as well.

Ultraviolet disinfection of water employs low-pressure mercury lamps. They generate short-wave ultraviolet in the region of 253.7 Angstroms which is lethal to microorganisms including bacteria, protozoa, viruses, molds, yeasts, fungi, nematode eggs and algae. The mechanism of micro-organism destruction is currently believed to be due to the fact that ultraviolet causes molecular rearrangements in DNA and RHA, which in turn blocks replication [5]. The acceptance of UV disinfection at wastewater plants treating in excess of one billion gallons daily is proof that UV is no longer an emerging technology, but rather an accepted technology used routinely by engineers to safeguard human health and alleviate environmental pressures.

One of the factors affecting the performance of UV disinfection is the quality of wastewater. The effectiveness of UV radiation for disinfecting high quality secondary or tertiary treated effluents has been demonstrated (e.g., [6-9]). However, there has been uncertainty regarding the performance of UV radiation for the disinfection of marginal or poor quality effluents and primary treated wastewater (e.g., [10-13]). A cause of this uncertainty is the presence of particle associated microorganisms, which may have a negative impact on the disinfection process. This problem is not unique to UV disinfection. Destroying micro-organisms within particles represents a challenge for many other disinfection processes such as chlorine $[14,15]$. High doses of disinfectants are usually required to expose microorganisms buried within the particles to lethal doses. Previous studies have shown that suspended particles in wastewater can increase microbial survival by shielding microorganisms from UV irradiation. Qualls et al. [16] observed significant greater disinfection effect in filtered effluent than in unfiltered effluent. Liltved and Cripps [17] reported improved overall bacteria removal from seawater using particle prefilters. Loge et al. [18] concluded that UV could not penetrate particles by transmission through solid material. In another study [19], factors including the concentration of particles and the concentration of dispersed (non-particle associated) coliform bacteria were identified to influence the formation of particle-associated coliform. A study on the effect of particle size indicated that a minimum particle size governs the ability of a particle to shield coliform bacteria from UV light [20]. Ormeci and Linden [14] found that naturally occurring particle-associated coliform survives at UV and chlorine disinfection doses typically applied in wastewater treatment plants. They reported that particle-associated coliform exhibits a slower inactivation rate and tailing, whereas non particle-asso- ciated coliform is more easily and rapidly inactivated. In their study, filtration was found to be effective in reducing particle-associated coliform and decreasing the total number of particles at all the particle sizes. Several investigations have reported a relationship between suspended solid concentration and fecal coliform survival in UV irradiated wastewater samples [12]. The synergistic use of UV with other forms of particle-penetrating irradiation in an integrated disinfection process is a potential option for addressing this issue. UV light disinfect aqueous solutions in different ways. In this case, disinfection might be accomplished more efficiently if the UV is carried out at low doses to inactivate the free microorganisms.

In the sequel, we will evaluate the kinetics of bacterial strains of Pseudomonas aeruginosa and study the influence of UV doses on the kinetics of disinfection in order to determine the best contact time-UV dose combination, which will be adopted to achieve a pre-determined target quality. Furthermore, we will analyse UV-resistant strains of Pseudomonas aeruginosa to underline the influence of suspended solids on the inactivation kinetics of these strains. Due to the scarcity of readily available information about the influence of temperature on microorganism inactivation processes subsequent to inactivation with UV radiation, a series of batch studies were performed at $5^{\circ} \mathrm{C}, 25^{\circ} \mathrm{C}, 37.5^{\circ} \mathrm{C}$ and $50^{\circ} \mathrm{C}$. We shall study the impacts of UV irradiation of both on bacterial strains of $P$. aeruginosa inactivation in primary and secondary wastewater effluents and show the influence of filtration on the process of disinfection of water by UV irradiation.

\section{Materials and Methods}

\subsection{Experiments}

The laboratory UV-device was earlier described by Hassen $e t$ al. [21] and it was built with the cooperation of the company Guy Daric S.A (Aubervilliers, France). This apparatus was used for the UV irradiation of samples. This prototype contained a sliding rack, with an irradiation board, which could receive at the same time six Petri dishes of $90 \mathrm{~mm}$ diameter. A germicidal low-pressure mercury vapour discharge lamp (length $=900 \mathrm{~mm}$, diameter $=13 \mathrm{~mm}$, power of UV emission at $254 \mathrm{~nm}=65$ W) with reflector could be adjusted in height above the irradiation board. The lamp was supplied via electric ballast and the ozone produced in the irradiation room was removed by an extractor. The UV irradiance was measured with a calibrated radiometer (IL1700, International Light). Prior to each test, the UV transmittance (the fraction of UV intensity transmitted through $1 \mathrm{~cm}$ path length of the sample) was measured using a UV spectrophotometer (P254C UV Photometer, Trojan Technologies). The concentration of total suspended solids 
(TSS) was measured according to the American Public Health Association (APHA) standard method 2540 C [22]. The treated wastewater samples used in this study were collected at the outlet of trickling filter at the level of a pilot wastewater treatment plant (WWTP) belonging to the Water Research and Technology Center, Tunisia. The pilot WWTP is connected to the sewerage network of the city of Tunis and has a processing capacity of 150 $\mathrm{m}^{3}$ per day. It is composed of four treatment lines operating in parallel: trickling filter, rotating biological discs, soil and lagoon optional filter. During disinfection tests, the physio-chemical characteristics of the treated wastewater by trickling filter did not significantly change. The UV transmittances of the primary and secondary wastewater effluents were $27 \%$ and $49 \%$, respectively. The total suspended solids (TSS), in the primary and secondary wastewater effluents ware $62 \mathrm{mg} \cdot \mathrm{L}^{-1}$ and $27 \mathrm{mg} \cdot \mathrm{L}^{-1}$, respectively. The values fluctuated between 20 to 29 $\mathrm{mg} \cdot \mathrm{L}^{-1}$ for $\mathrm{BOD}_{5}$ and 90 to $102 \mathrm{mg} \cdot \mathrm{L}^{-1}$ for COD.

\subsection{Experiments in a Batch Laboratory Irradiation Device}

All bacterial strains studied were cultivated to mid-log phase at $37^{\circ} \mathrm{C}$ in $20 \mathrm{ml}$ of nutrient broth. Each culture was centrifuged at $5000 \mathrm{rpm} / \mathrm{min}$ for $15 \mathrm{~min}$ and the pellet was washed twice with sterile distilled water. The washed pellet was re-suspended in $10 \mathrm{ml}$ sterile distilled water. Test organisms were then seeded separately, into $20 \mathrm{ml}$ of sterile primary and secondary wastewater of UV transmittance $27 \%$ and $50 \%$, respectively, to give a viable cell count of approximately $10^{5}$ and $10^{7} / \mathrm{ml}$, the same mean count as in the primary and secondary wastewater suspension, and exposed to the UV light for times varying from 2 to $90 \mathrm{~s}$ (corresponding to 10.7 and 183 $\mathrm{mW} \cdot \mathrm{s} \cdot \mathrm{cm}^{-2}$ ). All irradiation experiments were performed at laboratory temperature of $25^{\circ} \mathrm{C} \pm 5^{\circ} \mathrm{C}$. Petri dishes of $90 \mathrm{~mm}$ diameter, containing $20 \mathrm{ml}$ of seeded wastewater, were shaken carefully with a mechanical shaker (Edmond Bühler) for at least 15 minutes in order to remove all bacterial aggregates. Seeded wastewater served for counting bacteria, before $\left(N_{0}\right)$ and after $(N)$ exposure to a definite UV dose. The layer of water crossed with UV rays was $3 \mathrm{~mm}$ deep and each experiment was repeated at least four times. Measurements of incident intensity at the liquid surface, at $254 \mathrm{~nm}$, were made with an Ultraviolet Products Vilbert-Lourmat digital radiometer. Doses expressed in $\mathrm{mW} \cdot \mathrm{s} \cdot \mathrm{cm}^{-2}$ were calculated as the average incident intensity multiplied by the exposure time and was regulated by controlling the exposure time. All experiments were made in triplicates.

\subsection{Pseudomonas aeruginosa Strains}

Experiments of disinfection were conducted using the species $P$. aeruginosa. The rationale for the choice of this species is that it is a ubiquitous strain that is commonly detected in surface water, wastewater, hospitals, air and even in the soil and plants and is easily cultivable. Additionally, it is the cause of several confirmed outbreaks and is highly resistant to disinfection [23]. Therefore, its kinetics of inactivation by UV irradiation resemble those of all other less resistant pathogens. A collection of 4 strains of $P$. aeruginosa were irradiated with different UV doses and conditioned by 7 singular contact times ranging between 2 and 90 seconds. This collection includes strains of $P$. aeruginosa ATCC $15442\left[\mathrm{PA}_{0}=\mathrm{S} 1\right]$ (provided by DIFCO, laboratory POBOX 331058, Detroit M 48232-7058 USA), and a laboratory strain of $P$. aeruginosa isolated in 1986 from wastewater (S21 = S2). The other two strains were isolated from wastewater and treated without a repetitive sequential dose of UV (S3 and S4). All the strains were grown in the laboratory on nutrient broth (Institute Pasteur Production) and were labeled as S1, S2, S3 and S4, respectively.

\subsection{Design of the Study}

The main objective of this study was to demonstrate the effect of temperature of wastewater on the kinetics and performance of the disinfection process using ultraviolet. To accomplish this objective, bacterial strains were cultivated to mid-log phase at $37^{\circ} \mathrm{C}$ in $20 \mathrm{ml}$ of nutrient broth. Each culture was centrifuged at $5000 \mathrm{r} / \mathrm{min}$ for 15 min [24] and the pellet was washed twice with sterile distilled water. The washed pellet was re-suspended in 19 $\mathrm{ml}$ sterile distilled water. Each $20 \mathrm{ml}$ of culture from each test organism were then seeded separately into 200 $\mathrm{ml}$ of sterile wastewater having a UV transmittance of $50 \%$, to give a viable cell count of approximately $10^{5}$ to $10^{6} / 100 \mathrm{ml}$, the same mean count as in the secondary wastewater.

Bacteria were exposed to a UV-C dose of $80 \mathrm{~mW} \cdot \mathrm{s} \cdot \mathrm{cm}^{-2}$. The UV-C dose $\left(\mathrm{mW} \cdot \mathrm{s} \cdot \mathrm{cm}^{-2}\right)$ supplied was calculated as a product of the average UV intensity rate into the reactor $\left(\mathrm{mW} \cdot \mathrm{s} \cdot \mathrm{cm}^{-2}\right)$ and the irradiation time (s). Irradiation was performed at room temperature, between 25 and $30^{\circ} \mathrm{C}$.

Test tubes $[25 \times 200 \mathrm{~mm}]$ with screw caps, borosilicate beakers 2 liters in volume for the preparation of contaminated water and water bath [GFL 1002 - 1013 series, Germany] were used to carry out the tests.

After UV-C irradiation, each $200 \mathrm{ml}$ suspension of bacteria was transferred into $20 \mathrm{ml}$ numbered Test tubes [25 $\times 200 \mathrm{~mm}$ ] with screw caps (95\% transparent for 360 $\mathrm{nm}$ light). To test the effects of temperature, the tests were carried out at temperatures of $5^{\circ} \mathrm{C}, 25^{\circ} \mathrm{C}, 37.5^{\circ} \mathrm{C}$ and $50^{\circ} \mathrm{C}$ using a water bath to vary the temperature, which was equipped with one fluorescent lamp (3.7 W; 
PHILIPS TLD). The test tubes were tilted by $45^{\circ}$ angle so that the water in the water bath covered one side of the tubes and the upper sides were subjected to UV. Irradiation periods were in the range of 60 to 480 minutes. The concentration of bacteria was measured every 60 minutes by using a pipette to take samples from each time.

\section{Results and Discussion}

\subsection{Behavior of $P$. aeruginosa Strains after UV Irradiation}

Both of $P$. aeruginosa issued from an environmental origin (S3 and S4) tested were isolated from wastewater and submitted to a sequential and alternate treatment of 2 or 4 minutes of exposure to $U_{254}$ rays, called passage. These successive passages of 2 or 4 minutes exposure to $U_{254}$ rays were performed in $90 \mathrm{~mm}$ Petri dishes. After each passage, the environment is enriched by a solution of 5 $\mathrm{ml}$ of Asparagine $(5 \mathrm{~g} / \mathrm{L})$ and incubated for 1 hour at $37^{\circ} \mathrm{C}$. Both strains tested S3 and S4 were exposed to 34 and 86 passages, respectively, and corresponding to a cumulative UV dose of 68,544 and $173,376 \mathrm{~mW} \cdot s \cdot \mathrm{cm}^{-2}$, respectively. Thus, we recorded a significant resistance to UV radiation for these two strains marked by good growth and intense pigmentation (release of pyoverdine or fluorescein known as a specific fluorescent pigment released by these species in some definite circumstances). In this sense, a study published by Hassen et al. [21] and recently by Lesavre and Magoarou [25], showed that the treatment of $P$. aeruginosa strains with low UV doses $\left(<30 \mathrm{~mW} \cdot \mathrm{s} \cdot \mathrm{cm}^{-2}\right)$ has significant effect on the growth stimulation of these bacteria. To confirm the acquisition of UV resistance of these two strains (S3 and S4), a kinetic inactivation study was carried out and an example of the experimental results obtained for the strain S4 is shown in Figure 1. As evident from the figure, the kinetics abatement of the strain S4 treated with UV differ significantly from that of the S4 strain of departure (not treated). Therefore, the sequential UV treatment of the starting strains S4 induced a significant resistance to UV radiation.

\section{2. $P$. aeruginosa Inactivation in Primary and Secondary Wastewater Effluent by UV Irradiation}

$P$. aeruginosa strains were inactivated when exposed to UV radiation. The inactivation rate of $P$. aeruginosa strains in all the cases was proportional to the radiation dose. When primary and secondary wastewater samples were exposed to UV irradiation, the number of $P$. aeruginosa decreased progressively with an increase in the UV dose (Figure 2). A dose of $50 \mathrm{~mW} \cdot \mathrm{s} \cdot \mathrm{cm}^{-2}$ was required for a 1 and $2 \mathrm{U}-\log$ inactivation of $P$. aeruginosa

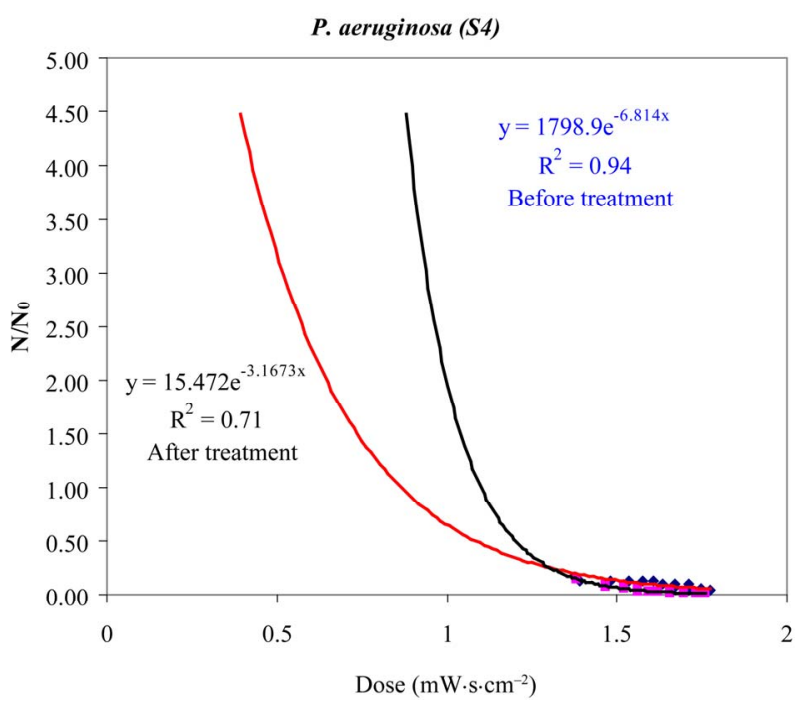

Figure 1. Inactivation of Pseudomonas aeruginosa (strain S4 for example) according to UV dose applied before and after a prolonged exposure to UV ray $N / N_{0}$ : Rate of inactivation of microorganisms after exposure to UV; $N$ : Number of bacteria after the period of exposure to laboratory light; $N_{0}$ : Number of microorganisms at the instant $T=0\left(N_{0}=10^{7}\right.$ organisms $/ 100 \mathrm{ml})$.

(S1) in the primary and secondary wastewaters, respectively. In contrast, it reached such a reduction of $P$. aeruginosa (S2) in the order of 2 and 3 U-Log for the same UV dose and in the same primary and secondary wastewaters, respectively.

The rate of $P$. aeruginosa strains inactivation progressively decreased as irradiation proceeded, until it reached a "plateau" region (see Figure 2). The number of $P$. aeruginosa for S1 and S2 levelled off at a higher concentration in the primary effluent than in the secondary effluent.

The difference observed in the inactivation of $P$. aeruginosa strains in the primary and secondary wastewater samples might be due to the quality of the water used in each experiment and to the difference in the ratio of free to particle-associated $P$. aeruginosa in initial counts. The initial count is governed by the concentration of free microorganisms in the samples. As the initial concentration increases, the effect of particles on the inactivation rate diminishes. This is particularly valid for the wastewater samples where the ratio of free to particle-associated microorganisms is greater in primary compared to secondary effluent. A quasi-empirical model, developed by Emerick et al. [20] to describe the inactivation of coliform bacteria with UV in wastewater, can be used to describe the results. The UV disinfection model takes into account the effect of free and particle-associated microorganisms, as follows:

$$
N(D)=N_{f} e^{-K D}+\frac{N_{p}}{K D}\left(1-e^{-K D}\right)
$$




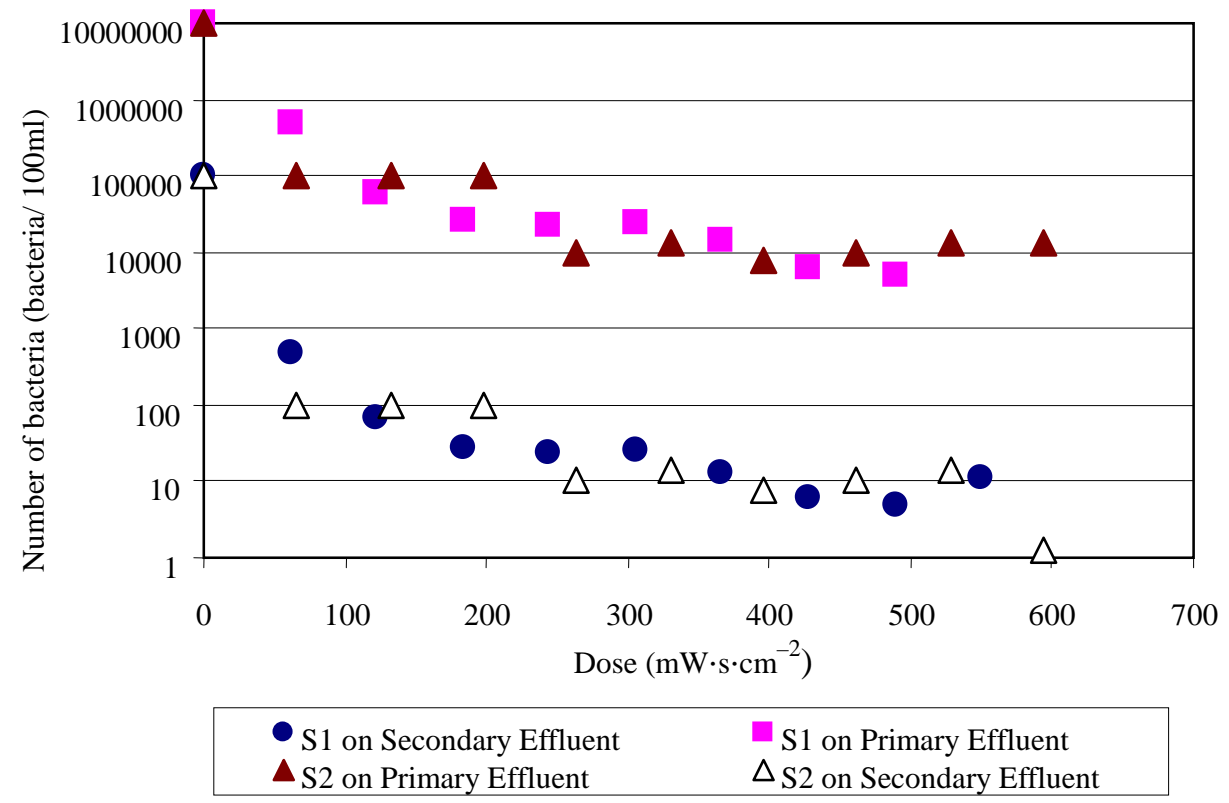

Figure 2. P. aeruginosa (S1 and S2) inactivation in primary and secondary wastewater effluent by UV irradiation (The error bars show $95 \%$ confidence intervals). $N / N_{0}$ : Rate of inactivation of microorganisms after exposure to UV; $N$ : Number of bacteria after the period of exposure to laboratory light; $N_{0}$ : Number of microorganisms at the instant $T=0\left(N_{0}=10^{7}\right.$ organisms $/ 100 \mathrm{ml}$ ).

where $N(D)$ is the number of surviving coliform bacteria after applied dose $D ; N_{f}$ is the total number of free (non particle-associated) coliform bacteria, $N_{p}$ is the total number of particles that contain one or more coliform, $D$ is the applied UV dose, and $k$ is the inactivation rate constant. The first term in the equation represents the exponential degradation of free microorganisms. The second term represents the slow inactivation of particle-associated microorganisms. Therefore, the greater the ratio of free to particle-associated microorganism (primary effluent in this case), the higher the initial inactivation rate. An other possible explanation for the slower inactivation rate in secondary effluent could be the difference in the form of typical $P$. aeruginosa bacteria before and after going through the biological treatment. The plateau phenomenon is primarily due to the shielding of UV radiation from microorganisms within particles [26]. Free microorganisms and those at particle surfaces are readily disinfected, but interior microorganisms require longer exposure times (higher apparent doses) to be exposed to the same dose that would inactivate free microorganisms [26]. The relatively slow inactivation of microorganisms associated with particulate material has been observed in other studies $[14,15,27]$. Some of the microorganisms can be associated with particles to an extent that they are completely shielded from UV irradiation [14]. The higher $P$. aeruginosa concentration in the plateau region of the primary effluent reflects the presence of a higher concentration of UV resistant particles in the primary effluent compared to the secondary effluent. This is likely the re- sult of a higher concentration of suspended solids in the primary samples. The ratio of the $P$. aeruginosa count in the "plateau" regions of the primary and secondary samples (Figure 2) is proportional to the ratio of the total suspended particles in the primary and secondary effluents. This is in agreement with the direct proportionality of fecal coliform survivor to suspended solids concentration in wastewater effluent, which is reported in other studies [12,16,26].

In a separate study, the impact of particle size on the ease of disinfection was investigated. A typical bacterial inactivation versus UV dose curve exhibits first-order kinetics at low doses. At higher doses, a deviation or tailing occurs due to shielding by particulates (Figure 3). The particles in the solids provide protection to microbes and thus higher UV doses are required to penetrate and kill all the bacteria. As a result, the application of increased UV doses results in diminishing returns in terms of additional microbial inactivation. Therefore, there is a bacterial density beyond which additional inactivation cannot be economically achieved. In such cases, alterations in up-stream processes that significantly improve effluent quality will have the added benefit of decreasing the UV dose required to achieve a desired disinfection limit. The potential effectiveness of UV disinfection will depend on the effectiveness of upstream treatment processes and the required level of inactivation. In order to validate this theory, Primary and secondary wastewater samples were subjected to filtration through 53 Micron pore size. The increased ease of disinfection with $53 \mathrm{Mi}$ - 


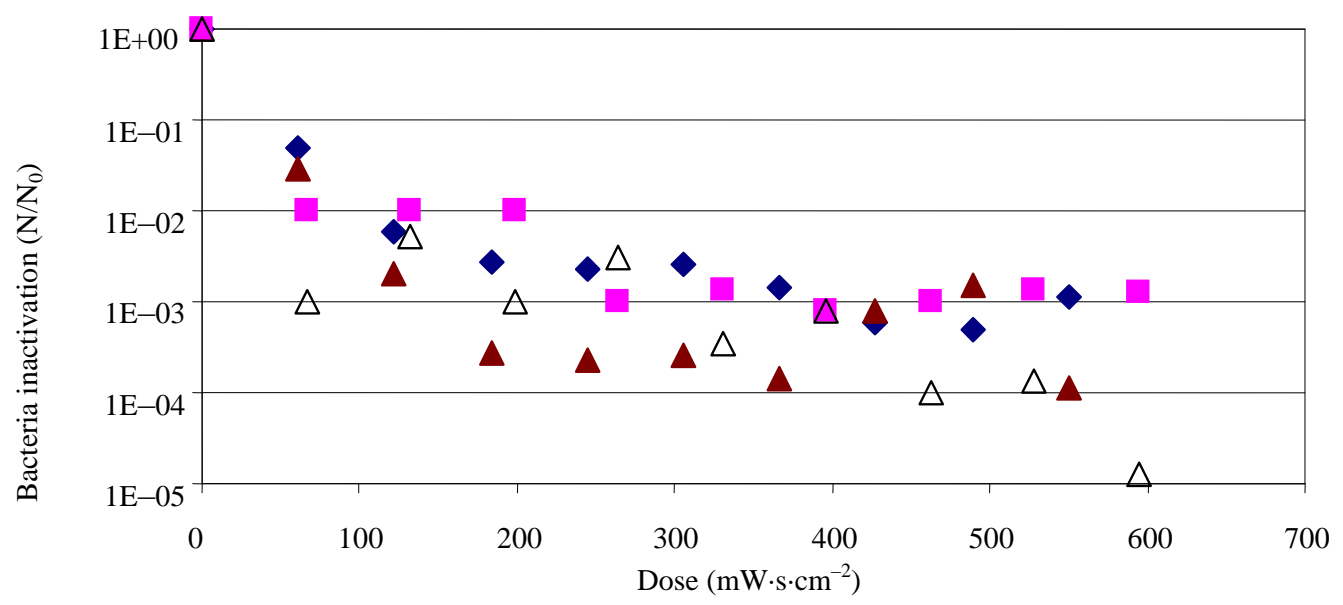

S1 in Whole Primary Effluent S2 in Whole Primary Effluent

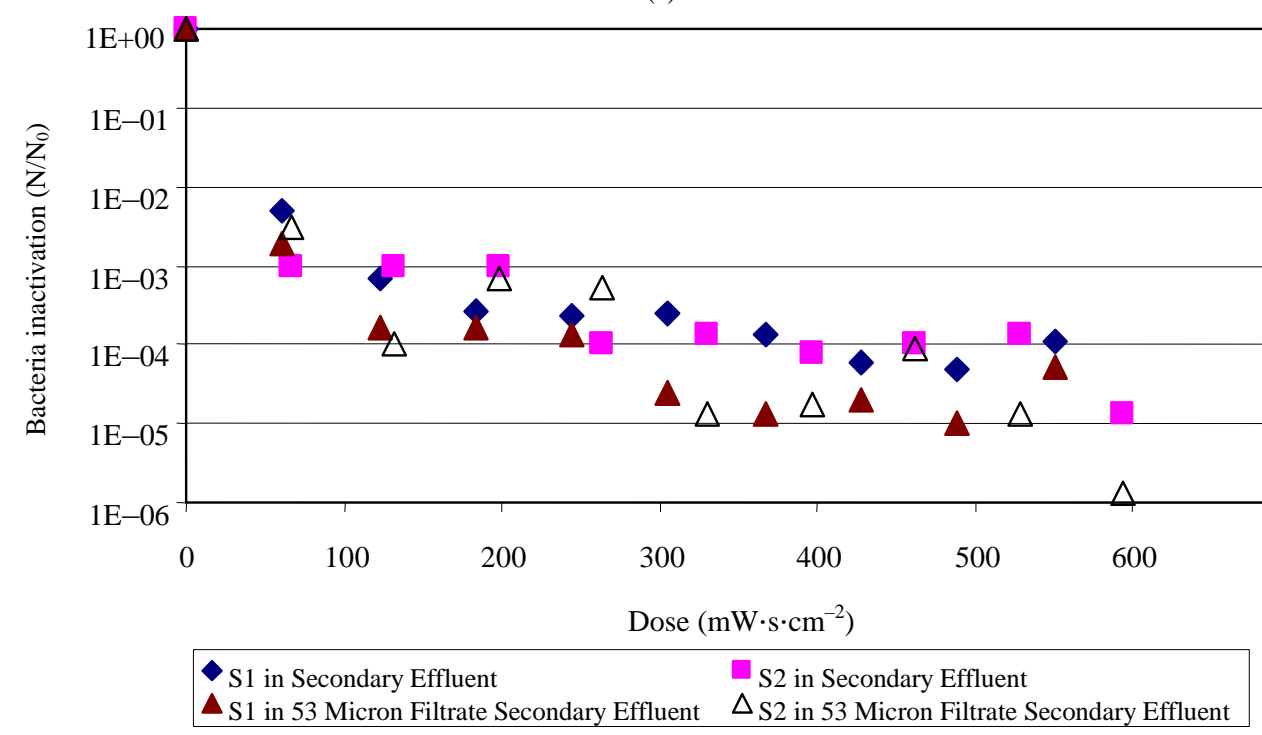

(b)
$\Delta \mathrm{S} 1$ in 53 Micron Filtrate Primary Effluent $\triangle \mathrm{S} 2$ in 53 Micron Filtrate Primary Effluent

(a)

Figure 3. $P$. aeruginosa (S1 and S2) inactivation in primary (a) and secondary wastewater (b) for filtered and unfiltered effluent by UV irradiation. (The error bars show $95 \%$ confidence intervals). $N / N_{0}$ : Rate of inactivation of microorganisms after exposure to UV; $N$ : Number of bacteria after the period of exposure to laboratory light; $N_{0}$ : Number of microorganisms at the instant $T=0\left(N_{0}=10^{7}\right.$ organisms $\left./ 100 \mathrm{ml}\right)$.

cron pore size in primary and secondary wastewater samples was reflected in the dose response curves of the filtrate samples (Figure 3). Filtration of the wastewater samples at a specific probe size is expected to eliminate the particles larger than the probe size and reduce the possibility of particle-associated microorganisms present in the sample. The improved overall bacterial removal efficiency by pre-filtration supports the hypothesis of bacteria associated with particles being protected from UV.

The inactivation curves (Figure 3) of $P$. aeruginosa by UV irradiation showed a 1 U-Log inactivation of bacteria strains (S1 and S2) in the 53 Micron Filtrate primary effluents compared to whole primary effluent. In contrast, the $P$. aeruginosa inactivation rate in the 53 Micron Filtrate secondary wastewater effluents was lower than those reported for the 53 Micron Filtrate primary effluents. The reason for the lower inactivation rate especially for doses between 0 and $300 \mathrm{~mW} \cdot s \cdot \mathrm{cm}^{-2}$ where the rate of inactivation did not exceed $1 \mathrm{U}$-Log, might be explained by the major role of bacteria filter that could eliminate the suspended matter likely to be associated with microorgan- isms in addition to the existence of many other chemicals in the effluent samples. Those chemicals, in particular carbonates, bicarbonates, and other organic compounds can react with water radiolysis products such 
as hydroxyl radicals, decreasing their availability to reach microorganisms and hence lowering the apparent inactivation rates. The $P$. aeruginosa iactivation rates were lower and did not exceed 1 U-Log especially for doses between 0 and $300 \mathrm{~mW} \cdot \mathrm{s} \cdot \mathrm{cm}^{-2}$ in 53 Micron Filtrate secondary and secondary wastewater effluents. This might be due to the nature of radical scavengers in wastewater before and after the biological treatment and the existence of certain compounds of smaller size than the pores of filters that may have colonized the effluent and agglomerated with the bacteria to prevent the penetration of radiation. The secondary biological treatment process employed is expected to oxidise some of the organic compounds in the wastewater. The concentration of many primary hydroxyl radical scavengers such as carbonates and bicarbonates, however, is not expected to change significantly as a result of biological treatment.

On the other hand, the increase of UV radiation dose rate between 300 and $700 \mathrm{~mW} \cdot \mathrm{s} \cdot \mathrm{cm}^{-2}$ on $P$. aeruginosa inactivation was investigated and showed that the inactivation rate increased by more than 1 U-Log for in 53 Micron Filtrate secondary compared to secondary wastewater effluents. This is probably attributed to the fact that the small pore filter was able to hinder the passage of certain compounds escaped the trickling filter. Similarly, high doses seem to be able to reach even some bacteria that are protected by solids of miniature sizes.

\subsection{Effect of Temperature on Process Kinetics}

As stated above, reference strains were exposed to an inactivating UV-C dose of $80 \mathrm{~mW} \cdot \mathrm{s} \cdot \mathrm{cm}^{-2}$ and were then carried out at temperatures of $5^{\circ} \mathrm{C}, 25^{\circ} \mathrm{C}, 37.5^{\circ} \mathrm{C}$ and $50^{\circ} \mathrm{C}$. Note that a number equal to or greater than $10^{2}$ organisms $/ 100 \mathrm{ml}$ of $P$. aeruginosa in treated wastewater poses a potential risk to the environment $[28,29] \mathrm{S} 1$ and S2 all showed variable results depending on the temperature and the time of incubation. Table 1 shows plots of UV doses against the logarithmic of inactivation of $P$. aeruginosa at various temperature of the disinfected secondary waste- water. Under normal operation conditions, i.e., $25^{\circ} \mathrm{C}-37.5^{\circ} \mathrm{C}$, the inactivation rate was not affected by the temperature of the disinfected wastewater. However, a low inactivation was observed when the operating temperature was reduced to $5^{\circ} \mathrm{C}$ regardless of the incubation time tested. In contrast, a considerable increase in the bacterial inactivation rate was noted when the system was operated to disinfect wastewater at $50^{\circ} \mathrm{C}$. The observed increase in the bacterial inactivation rate at $50^{\circ} \mathrm{C}$ might be explained by the decrease in the rate of repair enzyme activity as enzyme recovery occurs at elevated temperatures. Conversely, Studies of photoreactivation made by Kashimada et al. [30] showed that higher photoreactivation rates and levels were observed when exposed to near-optimum growth temperatures $\left(25^{\circ} \mathrm{C}\right.$ $37^{\circ} \mathrm{C}$ ) and photoreactivation levels were higher than those with very high $\left(50^{\circ} \mathrm{C}\right)$ or very low $\left(5^{\circ} \mathrm{C}\right)$ temperatures.

It is clear from Table 1 that the effect of changes in the temperature of the disinfected wastewater within the range $25^{\circ} \mathrm{C}-37.5^{\circ} \mathrm{C}$ on the kinetics of the process was not remarkable. It was found that the difference between the two means was not statistically significant, i.e., the temperature variation within the range $25^{\circ} \mathrm{C}-37.5^{\circ} \mathrm{C}$ had not effect on the kinetics of the effect UV disinfection process. Since UV irradiation occurs at room temperature $\left(20^{\circ} \mathrm{C}\right.$ to $25^{\circ} \mathrm{C}$ ), the reactivation experiences at the most extreme temperatures $\left(5^{\circ} \mathrm{C}\right.$ and $\left.50^{\circ} \mathrm{C}\right)$ could cause a temperature shock to the bacteria and therefore alter the reactivation process [28].

Hence, as $5^{\circ} \mathrm{C}$ and $50^{\circ} \mathrm{C}$ are outside the operating range of most treatment plants, as in our country, Tunisia, it is reasonable to assume that the effect of temperature change on the kinetics of UV disinfection process is negligible.

\section{Conclusions}

The disinfection of water by UV irradiation has become a credible alternative to chemical disinfection. A number of studies have been conducted to estimate the influence of physical factors and temperature, on the rates of die-

Table 1. Effect of temperature on the inactivation of $P$. aeruginosa bacteria by UV radiation.

\begin{tabular}{|c|c|c|c|c|c|c|c|c|c|c|c|c|c|c|c|c|}
\hline \multirow{3}{*}{ Temperature ${ }^{\circ} \mathrm{C}$} & \multicolumn{16}{|c|}{ Times (minutes) } \\
\hline & \multicolumn{2}{|c|}{60} & \multicolumn{2}{|c|}{120} & \multicolumn{2}{|c|}{180} & \multicolumn{2}{|c|}{240} & \multicolumn{2}{|c|}{300} & \multicolumn{2}{|c|}{360} & \multicolumn{2}{|c|}{420} & \multicolumn{2}{|c|}{480} \\
\hline & \multicolumn{16}{|c|}{ Abatement for S1 and S2, respectively (U-Log) } \\
\hline 5 & 2 & 2.3 & 2.1 & 2.2 & 2.2 & 2.7 & 2 & 2.5 & 2.4 & 2.9 & 2.5 & 2.9 & 2.2 & 2.7 & 2.8 & 3 \\
\hline 25 & 3.1 & 2.4 & 3.3 & 3.1 & 3.3 & 3.4 & 3.5 & 3.1 & 3.8 & 3.4 & 3.8 & 3.4 & 4 & 3.1 & 3.5 & 3.7 \\
\hline 37.5 & 3.7 & 2.9 & 3.7 & 3.5 & 3.9 & 3.8 & 3.1 & 2.8 & 3.1 & 3.1 & 2.8 & 2.4 & 2.2 & 2.6 & 2.6 & 2.9 \\
\hline 50 & 5 & 4.3 & 4.9 & 4.2 & 4.3 & 4.3 & 5.5 & 5 & 5.4 & 4.9 & 5.5 & 4.9 & 5.5 & 4.7 & 5.1 & 4.4 \\
\hline
\end{tabular}

Each number is an average of three readings. Tests were carried out using distilled water with negligible turbidity. 
off occurring for microbial pathogens in municipal wastewater. The results from this study indicate that temperature is a factor that influences the reduction percentage of bacteria and thus the efficiency of UV disinfection of contaminated water. Indeed, the bacterial inactivation when the system was operated to disinfect wastewater at $50^{\circ} \mathrm{C}$ was considerably higher than that observed when the operating temperature was reduced to $5^{\circ} \mathrm{C}$ irrespective of the incubation time tested. Changes in the temperature of the disinfected wastewater within the range $25^{\circ} \mathrm{C}-37.5^{\circ} \mathrm{C}$ proved to have negligible impact on the kinetics of the process. In fact, the difference between the two means was not statistically significant, i.e., the temperature variation within the range $25^{\circ} \mathrm{C}-37.5^{\circ} \mathrm{C}$ had no effect on the kinetics of the effect UV disinfection process. Hence, as $5^{\circ} \mathrm{C}$ and $50^{\circ} \mathrm{C}$ are outside the operating range of most treatment plants, as in our country, Tunisia, it is reasonable to assume that the effect of temperature change on the kinetics of UV disinfection process is negligible.

The presence of suspended particles in water had an important effect on dissipating the radiation energy and therefore on protecting the microorganisms against UV rays. As a conclusion, suspended particles have a direct impact on the effectiveness of the UV disinfection.

\section{Acknowledgements}

This study is supported by the European Union (Avicenna Project n 93AVI054). We express great appreciation to all the team of the laboratory of Water Treatment and Recycling, Borj-Cedria techno-park that contributed to realize this work, particularly to $\mathrm{Mr}$ Aissaoui, Hachemi and Ms Mabrouk; for their help.

\section{REFERENCES}

[1] A. Mc Donald and D. Kay, "Water Resources and Strategies,” Longman Scientific and Technical Press, New York, 1988.

[2] N. F. Oparaku, B. O. Mgbenka and C. N. Ibeto, "Waste Water Disinfection Utilizing Ultraviolet Light,” Journal of Environmental Science and Technology, Vol. 4, No. 1, 2011, pp. 73-78. doi:10.3923/jest.2011.73.78

[3] H. Kamani, F. R. Vaezi, A. R. Nabizadeh, Mesdaghinia and M. Alimohammadi, "Application of Medium Pressure UV Lamp for Wastewater Disinfection of Milk Production Industry,” Journal of Applied Sciences, Vol. 6, No. 4, 2006, pp. 731-734. doi:10.3923/jas.2006.731.734

[4] Anonymous, "Emerging Trends in UV Disinfection. Aquionics,” World Leader in Ultraviolet Technology, 2010. http://halmapr.com/news/aquionics/emerging-trends-in-uv disinfection/

[5] B. Eccleston, "UV Intensity Levels Affected by Water Quality,” Water Technology, Vol. 21, No. 5, 1998, pp. 61-68.
[6] USEPA, "Ultraviolet Disinfection Technology Assessment,” EPA 832-R-92-004, PB92-222868, US Environmental Protection Agency, Washington DC, 1992.

[7] E. R. Blatchley, K. C. Bastian, R. K. Duggirala, J. E. Alleman, M. Moore and P. Schuerch, "Ultraviolet Irradiation and Chlorination/Dechlorination for Municipal Wastewater Disinfection," Water Environment Research, Vol. 68, No. 2, 1996, pp. 194-204. doi:10.2175/106143096X127389

[8] J. L. Braunstein, F. J. Loge, G. Tchobanoglous and J. L. Darby, "Ultraviolet Disinfection of Filtrated Activated Sludge Effluent for Reuse Applications," Water Environment Re-search, Vol. 68, No. 2, 1996, pp. 152-161. doi:10.2175/106143096X127334

[9] A. J. Oppenheimer, J. G. Jacangelo, J. M. Lane and J. E. Hoagland, "Testing the Equivalency of Ultraviolet Light and Chlorine for Disinfection of Wastewater to Reclamation Standards,” Water Environment Research, Vol. 69, No. 5, 1997, pp. 14-24. doi:10.2175/106143097X125137

[10] O. K. Scheible, M. C. Casey and A. Forndran, "Ultraviolet Disinfection of Wastewater from Secondary Effluent and Combined Sewer Overflows,” EPA/600/2-86/005, PB86-145182, US Environmental Protection Agency, Cincinnati, 1986.

[11] G. Zukovs, J. Kollar, H. D. Monteith, K. W. A. Ho and S. A. Ross, "Disinfection of Low Quality Wastewaters by Ultraviolet Light Irradiation,” Journal of the Water Pollution Control Federation, Vol. 58, No. 3, 1986, pp. 199206.

[12] G. E. Whitby and G. Palmateer, "The Effect of UV Transmission, Suspended Solids and Photoreactivation on Microorganisms in Wastewater Treated with UV Light," Water Science and Technology, Vol. 27, No. 3-4, 1993, pp. 379-386.

[13] G. Sakamoto, "Clean Water for the 21st Century, Doing More for Less, UV Disinfection For Wastewater Reclamation," Proceedings of the 1997 PNPCA Annual Conference, Seattle, October 1997.

[14] B. Ormeci and K. G. Linden, "Comparison of UV and Chlorine Inactivation of Particle and Non-Particle Associated Coliform," Water Science and Technology: Water Supply, Vol. 2, No. 5-6, 2002, pp. 403-410.

[15] J. P. Dietrich, H. Basagaoglu, F. J. Loge and T. R. Ginn, "Preliminary Assessment of Transport Processes Influencing the Penetration of Chlorine into Wastewater Particles and the Subsequent Inactivation of Particle-Associated Organisms," Water Resources, Vol. 37, No. 1, 2003, pp. 139-149.

[16] R. G. Qualls, M. P. Flynn and J. D. Johnson, "The Role of Suspended Particles in Ultraviolet Disinfection,” Journal of the Water Pollution Control Federation, Vol. 55, No. 10, 1983, pp. 1280-1285.

[17] H. Liltved and S. J. Cripps, "Removal of particle-Associated Bacteria by Prefiltration and Ultraviolet Irradiation," Aquaculture Research, Vol. 30, No. 6, 1999, pp. 445-450. doi:10.1046/j.1365-2109.1999.00349.x

[18] F. J. Loge, R. W. Emerick, D. E. Thompson, D. C. Nelson and J. L. Darby, "Factors Influencing Ultraviolet Disinfection Performance, Part I: Light Penetration to Waste- 
water Particles,” Water Environment Research, Vol. 71, No. 3, 1999, pp. 377-381. doi:10.2175/106143097X122176

[19] F. J. Loge, R. W. Emerick, T. R. Ginn and J. L. Darby, "Association of Coliform Bacteria with Wastewater Particles: Impact of Operational Parameters of the Activated Sludge Process,” Water Resources, Vol. 36, No. 1, 2001, pp. 41-48.

[20] R. W. Emerick, F. J. Loge, T. R. Ginn and J. L. Darby, "Modeling the Inactivation of Particle Associated Coliform Bacteria," Water Environment Research, Vol. 72, No. 4, 2000, pp. 432-438. doi:10.2175/106143000X137969

[21] A. Hassen, M. Jemli, M. Nabli and A. Boudabous, "Disinfection of Wastewater by Ultravioletradiation in a Largescale Pilot Plant-Effect of Low Dose UV on Pseudomonas aeruginosa," Vector Environment, Vol. 30, 1997, pp. 75-81. doi:10.1016/S0960-8524(99)00179-0

[22] L. S. Clesceri, A. E. Greenberg,and A. D. Eaton, (Eds.), "Standard Methods for the Examination of Water and Wastewater," 20th Edition, American Public Health Association, Washington DC, 1998.

[23] P. Savoeurn, “Contribution to the Study of Pseudomonas aeruginosa Waterborne. Extraction and Put into Evidence of the Toxicity of Pyocyanin," Ph.D Thesis, University of Nancy I, Lorraine, 1983, p. 77.

[24] A. Hassen, M. Mahrouk, H. Ouazari, M. Cherif, A. Boudabous and J. J. Damelincourt, "UV Disinfection of Treated Waste Water in a Large-Scale Pilot Plant and Inactivation of Selected Bacteria in a Laboratory UV De- vice,” Bioresource Technology, Vol. 74, No. 2, 2000, pp. 141-150.

[25] J. Lesavre and P. Magoarou, "Méthodes de Mesure de la dose UV en déSinfection des eaux réSiduaires," Agence de l’Eau Seine-Normandie, Manterre, 2004.

[26] F. Taghipour, "Ultraviolet and Ionizing Radiation for Microorganism Inactivation,” Water Research, Vol. 38, No. 14, 2004, pp. 3940-3948. doi:10.1016/j.watres.2004.06.016

[27] A. Elkarmi, K. Abu-Elteen and A. Al-Karmi, "Disinfecting Contaminated Water with Natural Solar Radiation Utilizing a Disinfection Solar Reactor in a Semi-Arid Region,” Jordan Journal of Biological Sciences, Vol. 1, No. 2, 2008, pp. 47-45.

[28] B. Mounaouer, H. B. Noureddine, H. Helmi,and H. Abdennaceur, "Modeling of Secondary Treated Wastewater Disinfection by UV Irradiation: Effects of Suspended Solids Content,” Journal of Environmental Science, Vol. 22, No. 8, 2010, pp. 1218-1224. doi:10.1016/S1001-0742(09)60241-2

[29] K. D. Mena and C. P Gerba, "Risk Assessment of Pseudomonas aeruginosa in Water," Reviews of Environmental Contamination \& Toxicology, Vol. 201, 2009, pp. 71115. doi:10.1007/978-1-4419-0032-6 3

[30] K. Kashimada, N. Kamiko, K. Yamamoto and S. Ohgaki, "Assessment of Photoreactivation Following Ultraviolet Light Disinfection,” Water Science and Technology, Vol. 33, 1996, pp. 261-269. doi:10.1016/0273-1223(96)00428-3 